\title{
Aline Mura-Brunel, Silences du roman. Balzac et le romanesque contemporain
}

\section{Chiara Rolla}

\section{(2) OpenEdition}

1 Journals

\section{Edizione digitale}

URL: http://journals.openedition.org/studifrancesi/30782

DOI: 10.4000/studifrancesi.30782

ISSN: 2421-5856

\section{Editore}

Rosenberg \& Sellier

\section{Edizione cartacea}

Data di pubblicazione: 1 avril 2006

Paginazione: 192-193

ISSN: 0039-2944

\section{Notizia bibliografica digitale}

Chiara Rolla, «Aline Mura-Brunel, Silences du roman. Balzac et le romanesque contemporain», Studi Francesi [Online], 148 (XLX | I) | 2006, online dal 30 novembre 2015, consultato il 19 avril 2021. URL: http://journals.openedition.org/studifrancesi/30782 ; DOI: https://doi.org/10.4000/studifrancesi. 30782

Questo documento è stato generato automaticamente il 19 avril 2021.

\section{(c) (1)}

Studi Francesi è distribuita con Licenza Creative Commons Attribuzione - Non commerciale - Non opere derivate 4.0 Internazionale. 


\title{
Aline Mura-Brunel, Silences du roman. Balzac et le romanesque contemporain
}

\author{
Chiara Rolla
}

\section{NOTIZIA}

ALINE MURA-BRUNEL, Silences du roman. Balzac et le romanesque contemporain, Amsterdam-

New York, Rodopi, Coll. « Faux Titre », 2004, pp. 327.

1 In un percorso che spazia dalla Comédie humaine di Balzac per approdare ai romanzi del XXI secolo, la Mura-Brunel trova un denominatore comune alle opere che costellano questo lungo spazio cronologico: la potenza e l'eloquenza narrativa del silenzio. Se è vero che «Le roman est mort... depuis qu'il est né» (p. 5), altrettanto non può dirsi del romanesque, che invece perdura, si rinnova e si reinventa: per il romanzo contemporaneo esso consiste nella capacità di rilanciare la macchina narrativa in risposta ad un'ambizione di ordine ontologico che andrebbe a sostituire le mire storiche ed ideologiche del romanzo classico.

2 Secondo l'A. ciò che più evidentemente separa il romanzo del XIX e del XX secolo dalla produzione narrativa detta del contemporaneo estremo è allora un certo rapporto col silenzio. Analizzando una vasta rosa di autori contemporanei (des Forêts, Quignard, Gailly, Oster, Lenoir, Depussé, M.Petit, Laurens, Darrieussecq, Jauffret, Adely, Laurrent, Ernaux, Millet, Bergounioux, Michon, Juliet, per citarne solo alcuni) la Mura-Brunel mette in luce come il silenzio di volta in volta diventi principio poetico e oggetto del desiderio romanzesco.

3 I dodici capitoli che compongono il volume interrogano dunque lo statuto dell'opera narrativa dal punto di vista del suo rapporto col silenzio e ne mettono in evidenza due forme essenziali: da un lato un silenzio negativo, deleterio, che minaccia l'opera e inquieta l'artista; dall'altro il segno paradossale di una presenza, che consente di 
trasformare la paura di scomparire in possibilità supplementare di sopravvivenza: in fondo la scrittura altro non è che la prova che il silenzio è stato sconfitto. 